\title{
Final Report \\ Robust MR Thermometry for MRgHIFU in Breast and Liver: Joint Research between University of Utah and University of Geneva
}

Principal Investigators: Nick Todd, Dennis L. Parker, Rares Salomir

The Focused Ultrasound Surgery Foundation provided funding to our groups starting in June of 2010 for a research proposal titled, "Robust MR Thermometry for MRgHIFU in Breast and Liver: Joint Research between University of Utah and University of Geneva". The provided funds covered the salary for one postdoctoral research associate, time on the MR scanner, experimental supplies, travel between Utah and Geneva, and travel to several conferences. We are grateful for the support and are pleased to report that significant work has been done in the areas outlined in the proposal. Here we give a brief description of the work that was done during the 12 month funding period of the FUS Foundation award.

Collaboration between Utah and Geneva: The PI spent three weeks visiting and working at the MRgHIFU lab in Geneva from July $25^{\text {th }}$ to August $15^{\text {th }}, 2010$. The PI worked closely with the Geneva group members and participated in a number of experiments. The experience provided an invaluable opportunity to see another group at work and foster relations between the two groups.

\section{Work Completed:}

The reference-less temperature measurement technique developed by Dr. Salomir was implemented for breast imaging applications. A comparison of this technique against two other previously published methods was performed using in vivo breast imaging data sets from several volunteers. The results were presented as part of a talk at the 2010 Focused Ultrasound Surgery Foundation Symposium in Washington, DC.

A comparison study between polynomial reference-less MRT (developed by Stanford University work group) and near-harmonic reference-less MRT (developed by Geneva University work group) was initiated using data from MRgHIFU sonication in sheep liver in vivo.

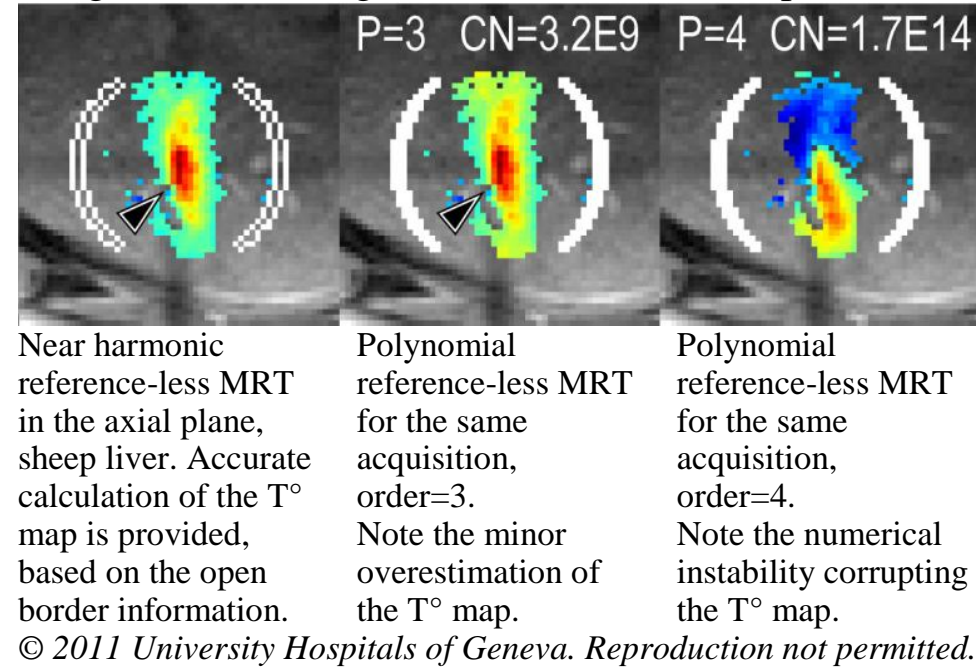

The polynomial fit method delivered correct temperature maps for the tested configuration under the following conditions: 1) a low order polynomial was sufficient to describe the background phase, and 2) the order of magnitude of the condition number $(\mathrm{CN})$ of the linear system was at least two units smaller than the number of significant digits of the computational platform. Violating the latter condition yielded numerical singularities and large errors in the calculated temperature maps. The near harmonic reconstruction of the background phase led to an accurate estimation of the temperature change in tissue for large ROIs.

A 3-D pulse sequence for MR temperature measurements was designed and implemented for breastspecific applications. The sequence is able to overcome problems particular to breast imaging including the presence of fat, out-of-FOV motion and small structures that can cause partial volume effects. The MR temperature maps obtained have good spatial resolution, high temporal resolution, and large 3-D volume 
coverage. The results of the temperature mapping technique were also presented as part of a talk at the 2010 Focused Ultrasound Surgery Foundation Symposium.

Work was done to extend the 3-D temperature mapping technique to other applications. The method was applied to brain imaging for transcranial MRgHIFU applications, providing larger coverage to monitor both the focus and any potential heating at bones surfaces. These results were presented at the 2011 ISMRM conference in Montreal. The method was also applied for analyzing volumetric HIFU heating trajectories. The results from this study were presented at the 2011 ISTU conference in New York. A paper describing the 3-D sequence, the reconstruction algorithm, and examples of several different applications was prepared, submitted to Magnetic Resonance in Medicine, and is currently in press. Further work on the technique was carried out this summer to improve its suitability for real-time applications. The initial results are promising and will be submitted as an abstract for ISMRM 2012.

The work on 3-D temperature mapping was part of an NIH R01 grant application. The grant proposed to use the 3-D sequence and reconstruction algorithm of the approach, but also to extend the method to involve ultrasound and thermal modeling for improved performance. The target application was transcranial MRgHIFU where large coverage is crucial for proper safety monitoring during treatments. The second submission of the grant (in November 2010) received an $8 \%$ and has now been awarded.

The MRgHIFU breast system that we designed in conjunction with Image Guided Therapy was assembled and tested this spring. The breast-specific design includes a 256-element phased array transducer, a coupling bath with reduced water volume, a comfortable patient table, and an in-house built 11-channel RF receive coil. Initial testing of the system has been on going with promising early results. Some of these results were presented at the ISMRM conference in Montreal and two papers have now been submitted describing the system and our preliminary results.

A hybrid PRF/T1 approach to simultaneously measuring phase and T1 changes is being developed. The T1 measurement is necessary due to the presence of fatty tissue in the breast. The pulse sequence for this method has been completed and initial testing is underway. The first results were presented at the ISMRM conference in Montreal and a full paper has now been submitted to Magnetic Resonance in Medicine. This work also forms the basis for an NIH Kirschstein grant application that was submitted by the PI this year. The grant has been awarded funding for two years, beginning September, 2011.

\section{Future Work:}

The PI and the Geneva group plan to extend their work on comparing reference-less methods in breast temperature imaging into a full length paper. This will require more patient data, which will be acquired this summer and fall. The Utah group will apply for additional funding based on their current NIH R01 on designing a breast-specific MRgHIFU system. The renewal will include improvements in MR imaging capabilities and plans for an improved second generation system. Finally, the PI will continue work on T1-related methods for measuring temperature changes in fat.

We are very grateful that the Focused Ultrasound Surgery Foundation has provided us with this funding. It allowed us to carry out important work and make advancements in several areas. It has also crucially allowed us to apply for and obtain further funding from the NIH, which will sustain these projects for a number of years into the future.

List of Papers, Abstracts, and Grants: The PI and the MRgHIFU teams at the University of Utah and University of Geneva have been productive during the 15 months of funding, submitting papers and abstracts and successfully getting a number of different grants funded. This includes talks at the FUS Foundation Symposium, a number of posters presented at ISMRM 2011 and ISTU 2011, a number of papers accepted for publication, and several grants submitted, including three that have been funded. 


\section{Papers:}

- $\quad$ N. Todd, M. Diakte, A. Payne, D.L. Parker. A Hybrid PRF/T1 Technique for Simultaneous Temperature Monitoring in Adipose and Aqueous Tissues. Submitted to Magnetic Resonance in Medicine.

- A. Payne, R. Merrill, E. Minalga, U. Vyas, J. de Bever, N. Todd, R. Hadley, E. Dumont, L. Neumayer,

D. Christensen, R Roemer, D.L. Parker. The Design and Initial Evaluation of a breast-specific MRgHIFU device. Submitted to Medical Physics.

- E. Minalga, A. Payne, R. Merrill, N. Todd, D.L. Parker, J.R. Hadley. An 11-Channel Phased Array Radio Frequency Coil for Magnetic Resonance Guided High Intensity Focused Ultrasound. Submitted to Magnetic Resonance in Medicine.

- $\quad$ N. Todd, U. Vyas, J. de Bever, A. Payne, D.L. Parker. Reconstruction of fully 3-D high spatial and temporal resolution MR temperature maps for retrospective applications. Magnetic Resonance in Medicine, In press, 2011.

- $\quad$ N. Todd, U. Vyas, J. de Bever, A. Payne, D.L. Parker. The Effects of Spatial Sampling Choices on MR Temperature Measurements. Magnetic Resonance in Medicine, 65: 515 - 521 (2011).

- K-H. Nam, A. Payne, N. Todd, X. Liu, J. Shea, P. Mohan, C. Scaife, A. Kennedy, D. Parker, E-K. Jeong, N. Rapoport, Combining Imaging and Targeted Chemotherapy: Acoustic, Imaging, and Therapeutic properties of block copolymer stabilized perfluoro-15-crown-5-ether nanoemulsions. Journal of Controlled Release, In press, 2011.

- N. Rapoport, K.-H. Nam, R. Gupta, Z. Gao, P. Mohan, A. Payne, N. Todd, X. Liu, T. Kim, J. Shea, C. Scaife, D.L. Parker, E-K Jeong, A. M. Kennedy, Ultrasound-mediated tumor imaging and nanotherapy using drug loaded, block copolymer stabilized perfluorocarbon nanoemulsions. Journal of Controlled Release, In press, 2011.

- A. Payne, U. Vyas, N. Todd, J. de Bever, D. Christensen, D. Parker. The effect of electronically steering a phased array transducer on near-field heating. Medical Physics, In Review, 2011.

- Auboiroux V, Dumont E, Petrusca L, Viallon M, Salomir R. An MR-compliant phased-array HIFU transducer with augmented steering range, dedicated to abdominal thermotherapy. Phys. Med. Biol. 2011; 56:3563-3582.

- $\quad$ R. Salomir, M. Viallon, A. Kickhefel, J Roland, D.R. Morel, L. Petrusca, V. Auboiroux, Th. Goget, S. Terraz, C. D. Becker, P. Gross. Reference-free PRFS MR-thermometry using near-harmonic 2D reconstruction of the background phase. IEEE Trans Med Imaging. In Review, 2011.

\section{Abstracts:}

- $\quad$ N. Todd, H. Odeen, A. Payne, L. Marsac, D. Chauvet, M. Pernot, A-L. Boch, J-F. Aubry, M. Tanter, D. L. Parker. Full coverage 3D temperature mapping for transcranial MRgHIFU applications. International Society for Magnetic Resonance in Medicine, Montreal, Cananda, \#1736, 2011.

- $\quad$ N. Todd, U. Vyas, J. de Bever, A. Payne, D.L. Parker. 3D Volume MR Temperature Mapping for HIFU Heating Trajectory Comparisons. International Society for Therapeutic Ultrasound, New York, 2011.

- U Vyas, A Payne, N Todd, D Parker, R Roemer, D Christensen. Non-invasive estimation of patientspecific tissue acoustic properties for MRgFUS. International Society for Therapeutic Ultrasound, New York, 2011.

- $\quad$ M. Diakite, N. Todd, D.L. Parker. Improved hybrid PRF-T $T_{1}$ pulse sequence for accurate $T_{1}$ mapping in high field $(\geq 3 T)$. International Society for Magnetic Resonance in Medicine, Montreal, Canada, \#1768, 2011.

- J. de Bever, A. Payne, N. Todd, and R. Roemer. Model-Predictive Controller using MR Thermometry for Dynamic Optimization of Heating/Cooling Pulses for HIFU Therapies. International Society for Magnetic Resonance in Medicine, Montreal, Canada, \#3720, 2011. 
- U. Vyas, A. Payne, N. Todd, D. Parker, R. Roemer, and D. Christensen Changes in attenuation coefficient in MRgFUS treatments of in-vivo rabbit thigh estimated using MRTI derived specific absorption rate patterns. International Society for Magnetic Resonance in Medicine, Montreal, Canada, \#1739, 2011.

- E Minalga, A Payne, R Merrill, N Todd, D Parker, R Hadley. Design and evaluation of radio frequency coils for magnetic resonance guided high intensity ultrasound. International Society for Magnetic Resonance in Medicine, Montreal, Canada, \#1726, 2011.

- N. Todd, A. Payne, U. Vyas, J. de Bever, R. Salomir, D.L. Parker. High Resolution and Large Volume Coverage MR Temperature Measurements in Breast. Focused Ultrasound Surgery Foundation Symposium, Washington DC, talk BC1, 2010.

- V. Auboiroux, M. Viallon, J-N. Hyacinthe, J. Roland, L. Petrusca, T. Goget, P. Gross, C. D. Becker, R. Salomir. ARFI-prepared MR-guided transcostal HIFU in sheep liver in vivo using a high resolution hybrid ARFI/MRT GRE-EPI sequence. International Society for Magnetic Resonance in Medicine, Montreal, Canada, \#524, 2011.

- L. Petrusca, P. Arnold, T. Goget, Z. Celicanin, V. Auboiroux, M. Viallon, F. Santini, V. De Luca, S. Terraz, C. Tanner, K. Scheffler, CD. Becker, P. Cattin, R. Salomir, Simultaneous Ultrasound/MRI Motion Monitoring in the Abdomen, $8^{\text {th }}$ International MRI Symposium, Leipzig, 2010

- L. Petrusca, M. Viallon, T. Goget, S. Terraz, D. Morrel, X. Montet, V. Auboiroux, CD. Becker, R. Salomir, Ablation ciblée dans le cortex rénal par MRgHIFU: faisabilité et complications opératoires sur gros animal, Journées Françaises de Radiologie, Paris, 2010

- L. Petrusca, M. Viallon, T. Goget, D. Morel, V. Auboiroux, S. Terraz, CD. Becker, R. Salomir, Volumetric MRgHIFU Rapid Ablation under Automatic Temperature Control: Accurate NonParametric Controller and Comparison of Different Sonication Patterns, MR-guided FUS Symposium, Washington DC, USA, 2010

- L. Petrusca, V. De Luca, P. Arnold, Z. Celicanin, T. Goget, V. Auboiroux, M. Viallon, F. Santini, S. Terraz, K. Scheffler, CD. Becker, C. Tanner, P. Cattin, R. Salomir, Ultrasound/MR hybrid imaging: truly simultaneous motion monitoring in the abdomen and image co-registration, International Symposium of Magnetic Resonance in Medicine, Montreal, Canada, \#628, 2011

\section{Grants:}

- NIH R01 EB13433A1 2010: Improved MRI temperature imaging using a subject-specific biophysical model. 2011. Currently Funded.

- Focused Ultrasound Surgery Foundation. Method for fully $3 D$ volumetric thermometry, with application to transcranial MRgFUS of the brain. 2011. Currently funded.

- NIH Kirschstein Award for Post Doctoral Fellows, F32 EB012917-01. MR Temperature Measurements in Fat During MR-Guided HIFU Treatments. Funded, to be activated 9/30/2011. 